\title{
Height Growth of Korean Pine Seedlings Planted under Strip-Cut Larch Plantations in Northeast China
}

\author{
Toshiaki Owari, ${ }^{1}$ Shinichi Tatsumi, ${ }^{2}$ Liangzhi Ning, ${ }^{3}$ and Mingfang Yin $^{4}$ \\ ${ }^{1}$ The University of Tokyo Hokkaido Forest, Graduate School of Agricultural and Life Sciences, The University of Tokyo, \\ 9-61 Yamabe-Higashimachi, Furano 079-1563, Japan \\ ${ }^{2}$ Graduate School of Environment and Information Science, Yokohama National University, 79-7 Tokiwadai, \\ Hodogaya-ku, Yokohama 240-8501, Japan \\ ${ }^{3}$ Dabiangou Forest Farm of Qingyuan County, 303 Provincial Road, Fushun, Liaoning 113311, China \\ ${ }^{4}$ College of Forestry, Shenyang Agricultural University, 120 Dongling Road, Shenyang, Liaoning 110161, China
}

Correspondence should be addressed to Toshiaki Owari; owari@uf.a.u-tokyo.ac.jp

Received 9 April 2015; Accepted 16 June 2015

Academic Editor: Robin Reich

Copyright (C) 2015 Toshiaki Owari et al. This is an open access article distributed under the Creative Commons Attribution License, which permits unrestricted use, distribution, and reproduction in any medium, provided the original work is properly cited.

\begin{abstract}
To develop two-storied forest management of larch plantations in Northeast China, this study examined the height growth of Korean pine (Pinus koraiensis Sieb. et Zucc.) seedlings planted under strip-cut larch canopies. We measured the height growth of the underplanted seedlings 4 years after planting. The larch canopies were of varying stand age (12, 17 , and 37 years) and stripcut width $(4.5,6.0$, and $7.5 \mathrm{~m})$. We measured the seedling height growth in an open site (i.e., a site with no canopy). Underplanted seedlings had a smaller height growth $\left(12.1-20.1 \mathrm{~cm}_{\text {year }}{ }^{-1}\right)$ than the seedlings planted in the open site $\left(23.7 \mathrm{~cm}_{\text {year }}{ }^{-1}\right)$. The seedlings underplanted in the wider strip-cuts tended to have greater height growth than the seedlings underplanted in the narrowest stripcuts. A generalized linear mixed model analysis predicted the greatest seedling height growth in the open site. A 36-47\% reduction in annual height growth was predicted for the narrowest strip-cuts $(4.5 \mathrm{~m})$ versus the open site, while a $13-36 \%$ reduction in annual height growth was predicted for the wider strip-cuts $(6.0-7.5 \mathrm{~m})$ versus the open site. To maintain adequate height growth, forest managers are recommended to create wider strip-cuts (i.e., $\geq 6.0 \mathrm{~m}$ ) for the purpose of underplanting Korean pine seedlings in larch plantations.
\end{abstract}

\section{Introduction}

Larches (Larix spp.) are important fast-growing and highyield tree species in Northeast China, and government policy has keenly promoted larch plantations in the region [1]. According to the National Forest Resource Survey of 1988, there were 1.2 million hectares of larch plantations in the region [2]. However, short-rotation management of pure larch plantations may have some disadvantages, such as soil degradation, loss of biodiversity, high vulnerability to disease, and insect outbreaks [3,4]. To prevent water shortages and other environmental threats, a large proportion of the planted larch forest has been designated "ecological public welfare forest" where clear-cutting is prohibited [5].
To enhance ecosystem functioning while maintaining the economic benefits of larch plantations, a pressing need exists to develop alternative forest management regimes in Northeast China $[5,6]$.

Forest management whereby even-aged plantation monocultures are transformed to two-storied mixed-species stands has been practiced in many forests around the world [7-9]. Underplanting is combined with the partial cutting of the existing stand to promote the development of complex stand structure with multiple canopy layers and various tree sizes [9]. Two-storied forest management in which overstory larch trees are strip-cut and Korean pine (Pinus koraiensis Sieb. et Zucc.) seedlings are underplanted has been deemed a viable option in Northeast China $[6,10]$. Korean pine is an 
ecologically key species in the region, where mixed coniferbroad-leaved forests dominated by Korean pine are naturally distributed [11, 12]. Korean pine has great economic value, because it produces high-quality timber and commercial seeds for eating and medical use $[13,14]$.

Korean pine is shade-tolerant in the early stages of growth but becomes gradually shade-intolerant as it ages $[11,15]$. In Northeast China, Korean pine has frequently been planted in broad-leaved secondary forests to restore a climax-like vegetative cover; a large area of mixed forest has been established using this approach $[12,16]$. Previous studies have analyzed the growth characteristics of Korean pine planted under overstory canopies with results indicating that the light environment is an important factor influencing its growth [12, 16-19]. Consequently, additional research has examined the photosynthetic traits of Korean pine seedlings and saplings $[6,11,16,20-23]$. Limited knowledge exists on the growth patterns of Korean pine seedlings planted under the larch canopy openings created by strip-cutting operations.

The purpose of this study was to examine the height growth of Korean pine seedlings planted under the larch canopy openings created by different types of strip-cutting treatments in Northeast China. A case analysis was conducted at two-storied forest stands established in eastern Liaoning Province. We employed a statistical modeling technique to quantify the height growth of underplanted Korean pine seedlings. Overstory larch canopies and the width of strip-cut were used as surrogates of light conditions, and the possible effects on seedling size were analyzed based on the derived growth model. Our analysis aimed to find optimal levels of strip-width for securing adequate height growth. We concluded with a brief discussion of management implications for the practice of underplanting Korean pine in strip-cut larch plantations.

\section{Materials and Methods}

2.1. Study Site. We conducted this study at the Dabiangou Forest Farm of Qingyuan County in Liaoning Province $\left(42^{\circ} 00-02^{\prime} \mathrm{N}, 125^{\circ} 03-04^{\prime} \mathrm{E}, 480-520 \mathrm{~m}\right.$ above sea level). The forest is located in the mid to lower slopes of the mountainous area of the Changbai Mountain Longgang branch. The region has a marked continental monsoon climate featuring cold, dry winters and hot, rainy summers [24]. The mean annual temperature and mean annual precipitation are $5^{\circ} \mathrm{C}$ and $700-800 \mathrm{~mm}$, respectively, with a maximum temperature of $36.5^{\circ} \mathrm{C}$, a minimum temperature of $-37.7^{\circ} \mathrm{C}$, and a frost-free period of 120-125 days [6]. The major soil type is brown forest soil, with a soil depth of $30-50 \mathrm{~cm}$ [10]. The main plantation species in the region are conifers such as Larix kaempferi (Lamb.) Carr., Larix olgensis Henry, Pinus koraiensis, and Pinus tabulaeformis Carr. [25].

We conducted field surveys in five larch plantations that had been established previously by the Dabiangou Forest Farm as experimental stands $[6,26]$. The stands were composed of either L. olgensis or L. kaempferi. Based on the stand ages and the types of strip-cutting, we hereafter refer to these five plots as A12-W4.5, A12-W6.0, A17-W4.5, A17-W6.0, and A37-W7.5 (Table 1). The larches had originally been planted at a spacing of $1.5 \mathrm{~m} \times 1.5 \mathrm{~m}$ in each stand, although some trees had been thinned or were dead at the time of survey.

Different types of strip-cutting were conducted in a repetitive manner in spring 2008 [6, 26]. A12-W4.5 and A17W4.5 were strip-cut by 2-row removal with 2-row retention, A12-W6.0 and A17-W6.0 were strip-cut by 3-row removal with 3-row retention, and A37-W7.5 was strip-cut by 4-row removal with 3-row retention. A12-W4.5, A12-W6.0, A17W4.5, and A17-W6.0 were located on west/southwest-facing slopes with slope angles of $26-37 \%$, while A37-W7.5 was located on a steep east-facing slope with a slope angle of $49 \%$. These stands were located at the mid part of the slopes, and the strips were orientated in the slope direction (uphilldownhill). The forest floor was mostly covered by shrubs and herbs in A17-W4.5, A17-W6.0, and A37-W7.5, while the soil surface was partly exposed with sparse vegetative cover in A12-W4.5 and A12-W6.0.

In 2008, Korean pine seedlings were underplanted in the openings created by the strip-cuts [26]. The seedlings were planted by the Forest Farm according to the strip width: in a line with $2.0 \mathrm{~m}$ spacing at A12-W4.5, in a line with $1.2 \mathrm{~m}$ spacing at A17-W4.5, in two lines with $2.0 \times 1.2 \mathrm{~m}$ spacing at A12-W6.0, and $1.2 \times 1.2 \mathrm{~m}$ spacing at A17-W6.0. Despite the widest strip the seedlings were sparsely planted in a center line with $1.2 \mathrm{~m}$ spacing at A37-W7.5, because natural tree regeneration was also expected to occur.

We set up one rectangular plot $\left(234-612 \mathrm{~m}^{2}\right)$ in each stand. The plot A12-W4.5 spanned two strip openings while the other plots had one strip, in which Korean pine seedlings had been planted. The retained rows of larches on both sides of the strip(s) were included in the plot area. In each plot, the diameter at breast height $(\mathrm{DBH})$ and height for all larch trees had been measured by the Dabiangou Forest Farm every year. Table 1 summarizes the stand parameters of overstory larch trees within each plot (tree density, mean $\mathrm{DBH}$, mean tree height, and stand basal area).

Table 1 also shows the mean canopy openness (\%), which was measured in June 2012 by taking hemispherical photographs at four or five randomly selected locations above the underplanted Korean pine seedlings in each plot. The photographs were taken at breast height $(130 \mathrm{~cm})$ using a digital camera (GX200, Ricoh Company, Ltd., Tokyo, Japan) fitted with a fisheye lens (UWC-0195, FIT Corporation, Nagano, Japan). We used imaging software (Gap Light Analyzer ver. 2.0) to estimate the canopy openness [27]. Significant differences were found among the plots $(P<0.001$; oneway ANOVA). Generally, canopy openness was greater in the plots having older stand ages and wider strips after 4 years of the strip-cutting treatments.

In addition to the five plots mentioned above, we set up one $320 \mathrm{~m}^{2}$ control plot in a young plantation hereafter referred to as OPEN to examine seedling growth in open sites. The plot OPEN was located at a distance of $<5 \mathrm{~km}$ from the other plots and at the mid part of an east-facing slope with a slope angle of $44 \%$ where Korean pine and Korean spruce (Picea koraiensis Nakai) had been planted in 2007 alternately at a spacing of $2.0 \times 2.0 \mathrm{~m}$. Shrubs and herbs covered most of the forest floor. 


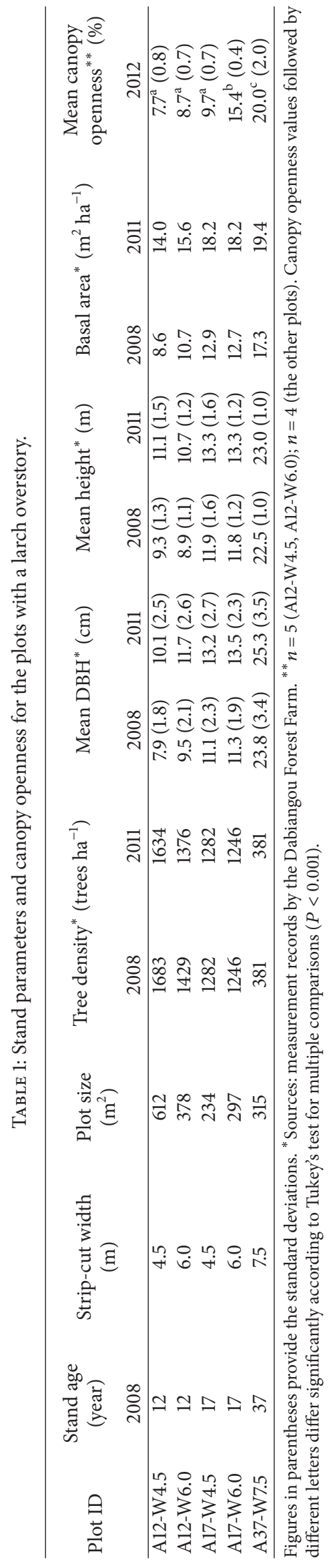


2.2. Data Collection and Analysis. Field measurement was conducted in mid-June 2012; four growing seasons after the Korean pine seedlings were underplanted in the larch plantations and five growing seasons after the planting in OPEN [26]. The annual height growth of Korean pine seedlings was estimated by measuring the distance between the successive terminal bud scars (internodes or branch whorls) along the main stems downward $[28,29]$ to a precision of $0.1 \mathrm{~cm}$. We assumed that the current-year shoot growth had completed by early June [15] and thus regarded the length of the new shoots as the height growth in 2012. The number of Korean pine seedlings in a given plot ranged from 9 to 25, with a total of 85 . The number of seedlings varied among the plots due to differences in plot size, initial planting density, and mortality. The mean rate of seedling survival was $66 \%$ (85/128), with the range between 39 and $79 \%$. The number of annual height growth measurements in a given plot ranged from 36 to 100 , with a total of 339 . We estimated the mean height of Korean pine seedlings for each plot and each growing season by subtracting the annual height growths backward from the current tree height. Because the homogeneity of variance assumption was questionable $(P<0.05$; Bartlett's test), we employed a nonparametric Scheffe's test for multiple comparisons to analyze differences between the plots.

Next, a generalized linear mixed model (GLMM) analysis [30] was conducted to examine the annual height growth of Korean pine seedlings under different canopy conditions. GLMM provides a flexible modeling framework that allows the handling of data with a nonnormal distribution and the incorporation of random effects [31]. We assumed that the logarithm of the height growth followed a normal distribution, because growth is a nonnegative continuous variable [32]:

$$
\log \left(G_{i j k}\right) \sim \operatorname{Norm}\left(\log \left(\bar{G}_{i j k}\right), \sigma^{2}\right),
$$

where $G_{i j k}$ is the observed annual height growth ( $\left.\mathrm{cm}_{\text {year }}{ }^{-1}\right)$ of seedling $i$ in plot $j$ at the $k$ th growing season, $\bar{G}_{i j k}$ is the expected annual height growth $\left(\mathrm{cm} \mathrm{year}^{-1}\right)$, and $\sigma^{2}$ is the variance.

Using the logarithmic link function [31], we expressed annual seedling growth as a function of three fixed effects, seedling height at the beginning of the growing season, basal area of overstory larch trees, and strip-cut width. We assumed that the effect of strip-cut treatment on height growth would vary according to residual overstory basal area. We included random effects to take into account the pseudoreplication within individual seedlings and plots. The growing years were considered as a temporal random effect:

$$
\begin{aligned}
\log \left(\bar{G}_{i j k}\right)= & \alpha_{0}+\alpha_{1} H_{i j k}+\left(\alpha_{2}+\alpha_{3} B_{j k}\right) W_{j}+\text { tree }_{i} \\
& +\operatorname{plot}_{j}+\text { year }_{k},
\end{aligned}
$$

where $H_{i j k}$ is the initial height $(\mathrm{cm})$ of seedling $i$ in plot $j$ at the beginning of the $k$ th growing season; $B_{j k}$ is the basal area $\left(\mathrm{m}^{2} \mathrm{ha}^{-1}\right)$ of overstory larch trees in plot $j$ at the $k$ th growing season; $W_{j}$ is a categorical variable that represents the stripcut width in plot $j$ (i.e., $4.5,6.0$, and $7.5 \mathrm{~m} ; W_{j}=0$ at OPEN); tree $_{i}$, plot $_{j}$, and year $k$ are the random-effect parameters for individual seedling $i$, plot $j$, and the $k$ th growing season; and $\alpha_{0}, \alpha_{1}, \alpha_{2}$, and $\alpha_{3}$ are fixed-effect parameters.

Backward stepwise selection method based on Akaike's information criterion (AIC) [33] was used to select the best model [34]. We evaluated the goodness of fit of the selected model by determining the coefficient of determination $R^{2}$ for GLMMs [35]. We further used a leave-one-out crossvalidation approach, because neither independent data nor enough data to split into two groups were available [36]. At each iteration, one observation was excluded from the data set and the selected model was fitted to the remaining observations [37]. The analyses were conducted using the "lme4" [38], "lmerTest" [39], and "MuMIn" [40] packages in the " $R$ " 3.0.3 statistical software [41].

Using the selected model with the estimated parameters, the annual height growth of Korean pine seedlings was predicted. We further simulated changes in seedling height in the early stages of growth by accumulating the predicted annual growth for each year. In the simulation, the initial seedling height at the time of planting was set at $20.0 \mathrm{~cm}$. Our computations were continued for 7 growing years after planting.

\section{Results}

3.1. Observed Height Growth of Korean Pine Seedlings. Figure 1 shows the changes in the observed mean height of Korean pine seedlings over the 4 years after planting. The initial height of individual seedlings at the time of planting (2007-2008) was $18.2-24.8 \mathrm{~cm}$, and there were no significant differences in mean height among the plots $(P=0.13-$ 1.00; Scheffe's test). The difference gradually got larger over time and became significant at 4 years after planting. A12W4.5 $(69.8 \mathrm{~cm})$, A17-W6.0 $(76.9 \mathrm{~cm})$, and A17-W4.5 $(79.6 \mathrm{~cm})$ had significantly lower mean seedling heights than OPEN (114.2 cm; $P<0.05)$, while A12-W6.0 (92.1 cm; $P=0.38)$ and A37-W7.5 $(101.0 \mathrm{~cm} ; P=0.85)$ did not have significant differences in seedling height from OPEN.

Significant positive correlations were found between the initial seedling height at the beginning of each growing season and the observed annual height growth at the growing season for each plot $(P<0.01$; Figure 2$)$, with Pearson correlation coefficients of $0.40-0.77$. The mean annual height growth was the largest in OPEN (23.7 $\left.\mathrm{cm} \mathrm{year}^{-1}\right)$, followed by A37-W7.5 (20.1 $\mathrm{cm}$ year $\left.^{-1}\right)$. All other plots (i.e., other than A37-W7.5) had significantly lower height growth (12.1$17.3 \mathrm{~cm}$ year $\left.^{-1}\right)$ than OPEN $(P<0.01$; Scheffe's test $)$.

3.2. Model Selection, Parameter Estimation, and Goodness of Fit. The GLMM inclusive of all three fixed effects (i.e., initial seedling height, stand basal area of overstory larch trees, and strip-cut width) was selected as the best model (Table 2), with the lowest AIC value of 167.4. The second smallest AIC value was 172.6, when basal area of overstory larch trees was excluded as a fixed effect. According to the parameter estimates, initial seedling height had a positive effect on the annual height growth. Additionally, the height growth of 
TABLE 2: Parameter estimates from the analysis of the annual height growth of Korean pine seedlings using a generalized linear mixed model.

\begin{tabular}{|c|c|c|c|c|c|}
\hline Variable (parameter) & Level & Estimate & Standard error & $t$ value & $P$ value \\
\hline Intercept $\left(\alpha_{0}\right)$ & & 2.6832 & 0.0807 & 33.24 & $<0.001$ \\
\hline Initial seedling height $\left(\alpha_{1}\right)$ & & 0.0089 & 0.0012 & 7.52 & $<0.001$ \\
\hline \multirow{3}{*}{ Strip-cut width $\left(\alpha_{2}\right)$} & $4.5 \mathrm{~m}$ & -0.8541 & 0.1478 & -5.78 & $<0.001$ \\
\hline & $6.0 \mathrm{~m}$ & 0.0650 & 0.2230 & 0.29 & 0.771 \\
\hline & $7.5 \mathrm{~m}$ & 0.6021 & 1.1893 & 0.51 & 0.613 \\
\hline \multirow{3}{*}{ Basal area of larch trees $\times$ Strip-cut width $\left(\alpha_{3}\right)$} & $4.5 \mathrm{~m}$ & 0.0227 & 0.0104 & 2.18 & 0.031 \\
\hline & $6.0 \mathrm{~m}$ & -0.0284 & 0.0153 & -1.86 & 0.064 \\
\hline & $7.5 \mathrm{~m}$ & -0.0435 & 0.0647 & -0.67 & 0.502 \\
\hline
\end{tabular}

Note: $\mathrm{AIC}=167.4$

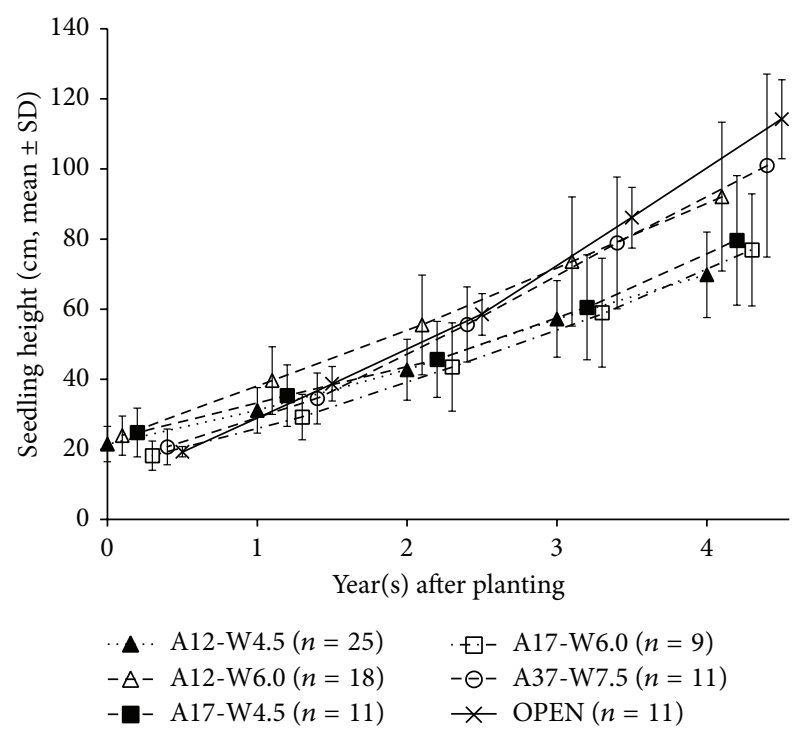

FIGURE 1: The observed mean height of Korean pine seedlings for 4 years after planting.

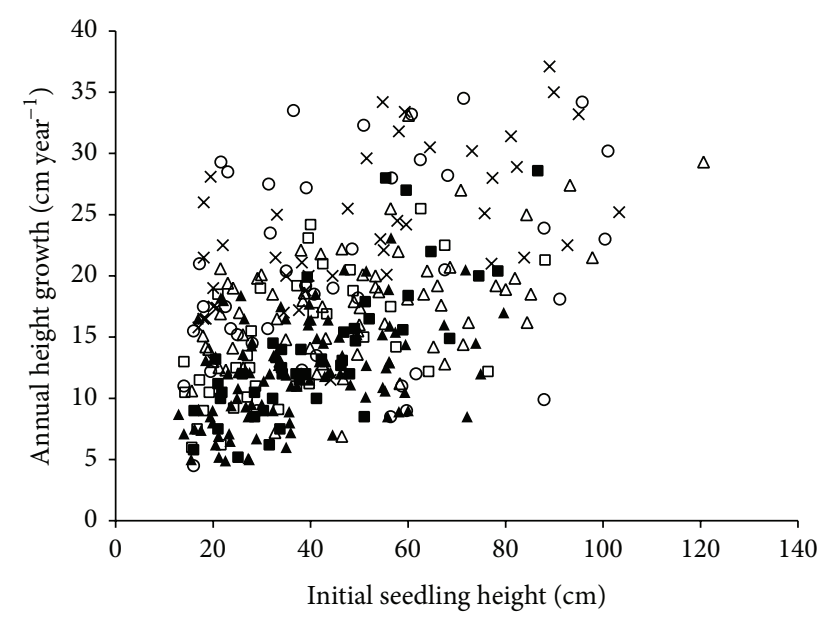
A A12-W4.5
$\triangle \mathrm{A} 12-\mathrm{W} 6.0$
$\square$ A $17-W 6.0$
O A $37-W 7.5$
- A17-W4.5
$\times$ OPEN

FIGURE 2: Relationships between the initial height at the beginning of the growing season and the annual height growth of Korean pine seedlings $(n=339)$.

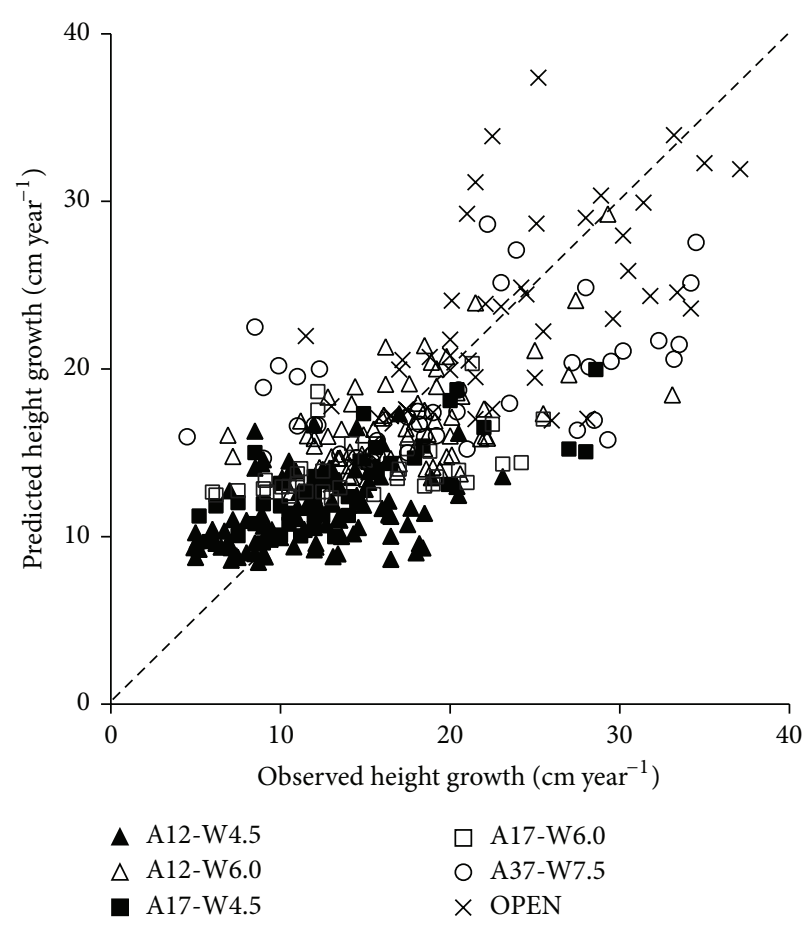

FIGURE 3: Relationships between observed and predicted annual height growth of Korean pine seedlings $(n=339)$. Leave-oneout cross-validation was used for the prediction. The dotted line represents the point of identical observed/predicted height growth.

underplanted seedlings in the narrowest strip-cut width (i.e., $4.5 \mathrm{~m}$ ) was significantly smaller than that in OPEN.

The selected model and its associated parameter estimates provided an acceptable fit to the data, with a marginal $R_{\mathrm{GLMM}(m)}^{2}$ (i.e., variance explained by fixed factors; [35]) of 0.49 and a conditional $R_{\mathrm{GLMM}(c)}^{2}$ (i.e., variance explained by fixed and random factors) of 0.55 . The leave-one-out cross-validation predictions fitted adequately to the observed height growth of seedlings $\left(R^{2}=0.51\right.$; Figure 3$)$, having a root mean square error of $4.7 \mathrm{~cm}$.

3.3. Predicted Height Growth of Korean Pine Seedlings. Figure 4 shows the predicted annual height growth of Korean pine seedlings as a function of initial seedling height and 


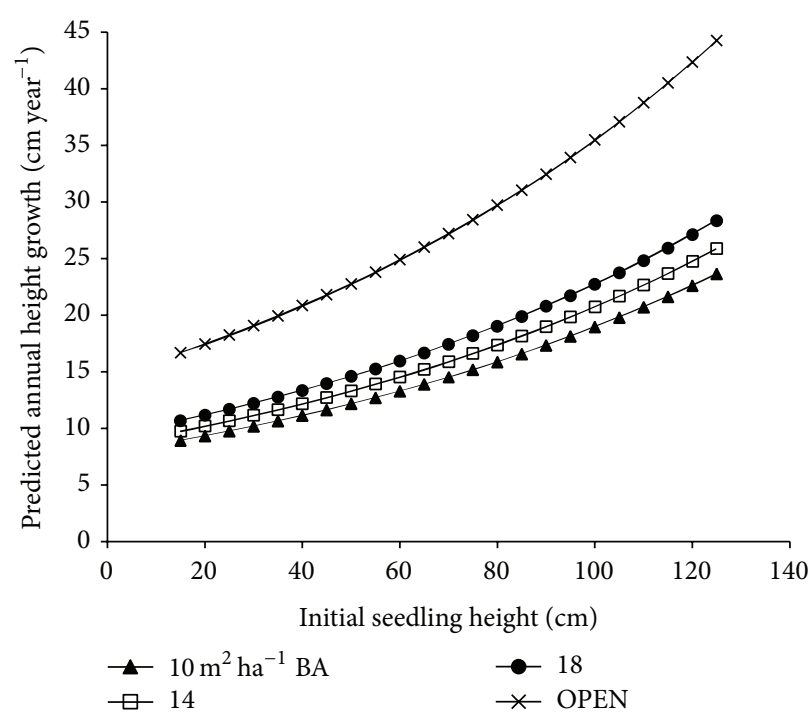

(a) Strip width: $4.5 \mathrm{~m}$

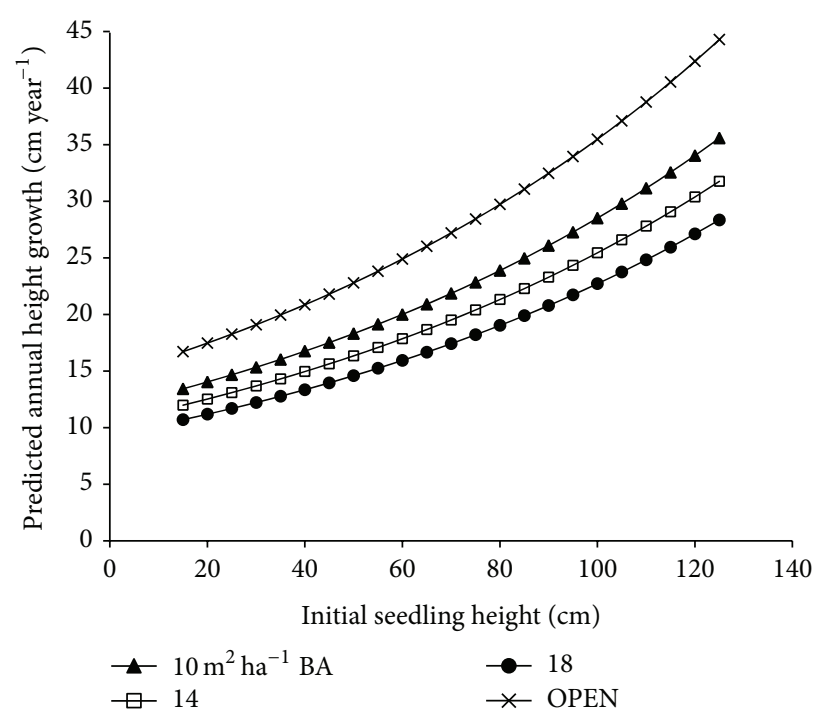

(b) Strip width: $6.0 \mathrm{~m}$

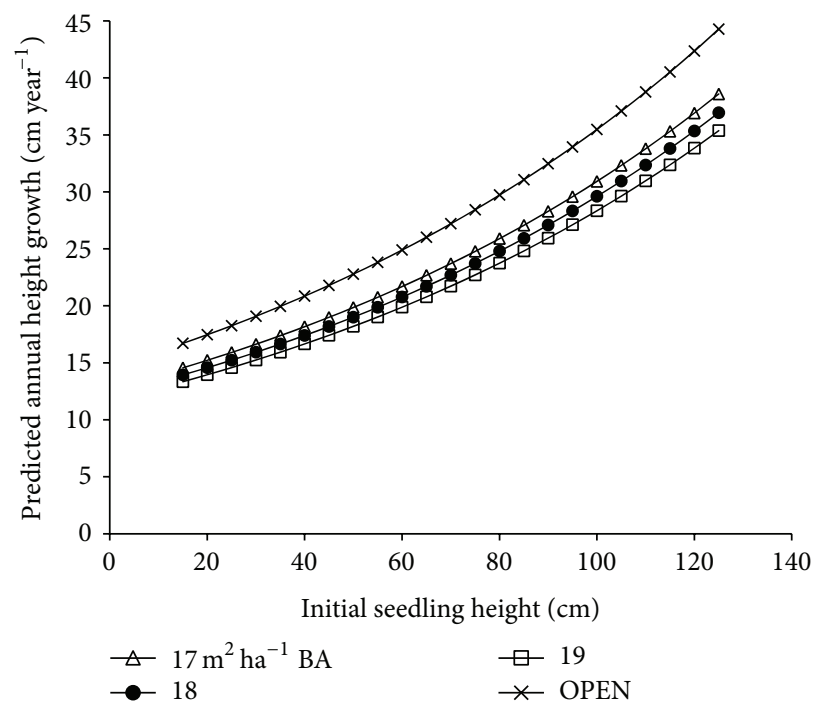

(c) Strip width: $7.5 \mathrm{~m}$

FIGURE 4: Relationships between the initial height and annual height growth of Korean pine seedlings, predicted by the generalized linear mixed model. In each strip-cut width, the basal area of overstory larch trees (BA) within a range of the plot data (Table 1) was used for the prediction.

stand basal area of overstory larch trees in each strip-cut width using the selected model (random-effect parameters were not used for the prediction). Seedlings planted in OPEN showed the largest predicted growth. The predicted growth of $120-\mathrm{cm}$ seedlings $\left(42.4 \mathrm{~cm}_{\text {year }}{ }^{-1}\right)$ was more than twice the predicted growth of $20-\mathrm{cm}$ seedlings $\left(17.4 \mathrm{~cm}_{\text {year }}{ }^{-1}\right)$. Generally, underplanted seedlings in wider strip-cuts tended to have relatively large height growth than those in narrower strip-cuts. That is, seedlings in the widest strip-cut (i.e., $7.5 \mathrm{~m}$ ) had the largest predicted growth, whereas height growth was strongly suppressed at the narrowest strip-cut (i.e., $4.5 \mathrm{~m}$ ). The annual height growths in the $4.5 \mathrm{~m}$ strip were $36-47 \%$ smaller than in OPEN. In the wider strip-cuts $(6.0-7.5 \mathrm{~m})$,
$13-36 \%$ reductions in annual height growth were predicted versus OPEN.

Figure 5 shows the predicted change in seedling height over a period of 7 years after planting in each strip-cut width using the selected model. The seedlings in OPEN were predicted to reach $301.6 \mathrm{~cm}$ after 7 years. The predicted seedling heights in the underplanted sites were smaller than those in OPEN. Seedling heights after 7 years in the $4.5 \mathrm{~m}$ strip were $109.4-112.9 \mathrm{~cm}$, which corresponded to $36-37 \%$ of the predicted seedling height in OPEN. In the wider strip-cuts $(6.0-7.5 \mathrm{~m})$, seedlings had greater predicted heights (136.8$222.9 \mathrm{~cm}$ ) after 7 years compared to the narrowest stripcut. 


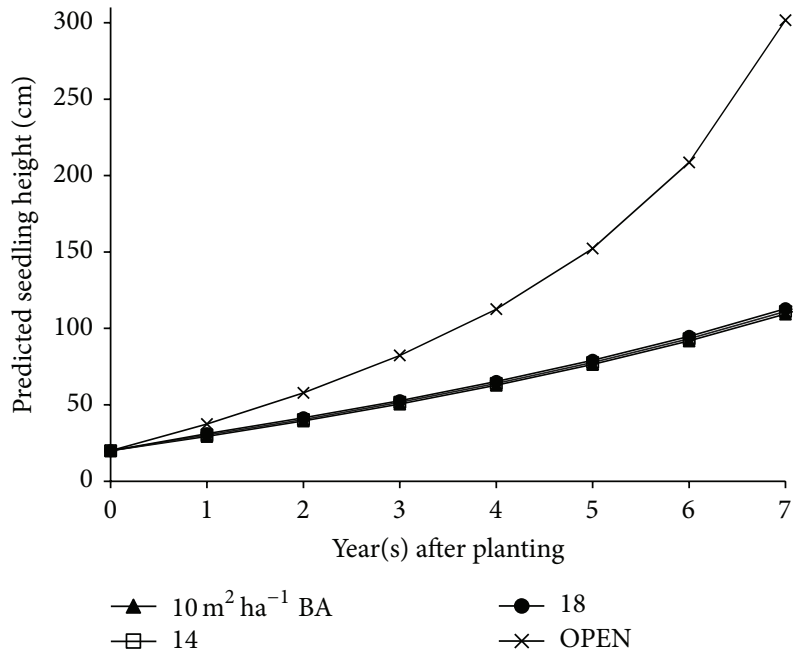

(a) Strip width: $4.5 \mathrm{~m}$

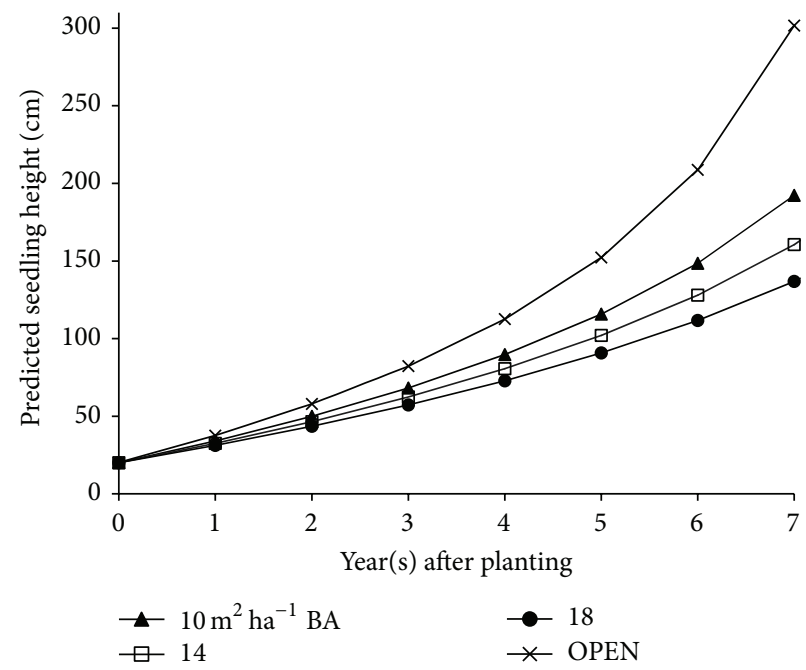

(b) Strip width: $6.0 \mathrm{~m}$

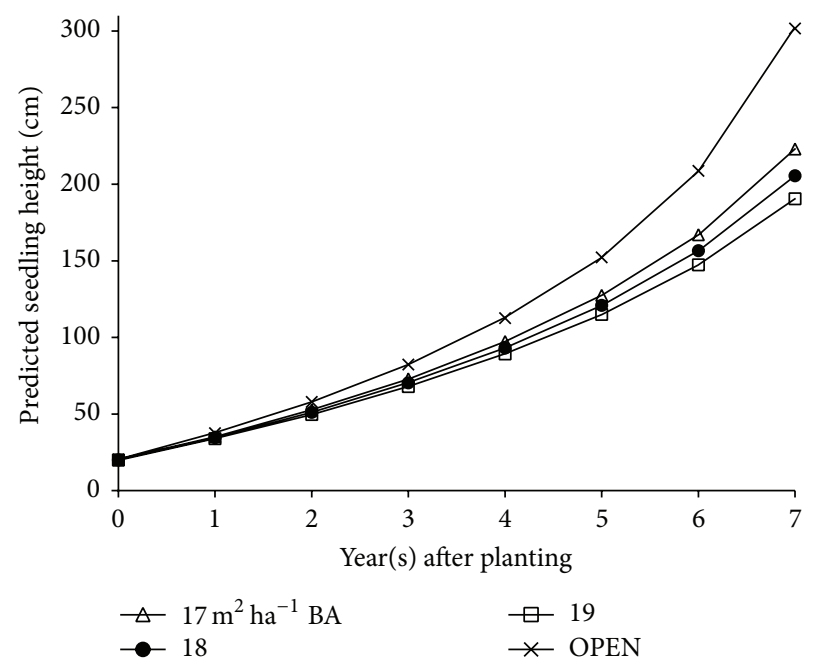

(c) Strip width: $7.5 \mathrm{~m}$

FIGURE 5: Predicted height of Korean pine seedlings for 7 growing years after plantation. The initial seedling height when planted was set at $20 \mathrm{~cm}$ for all plots, and the area of overstory larch trees (BA) was assumed to be constant over those 7 years.

\section{Discussion}

Our GLMM analysis successfully derived a statistical model that allows the assessment of annual height growth of Korean pine seedlings at the early stages of growing. The selected model and estimated parameters fit the observed height growth with an adequate predictive accuracy. The exponential growth pattern delineated in Figure 5 is consistent with our field observations (Figure 1), as well as a previous study by Liu and Wang [42], which found an exponential relationship between the height and age of Korean pine seedlings for 5 growing years after planting in the same region.

According to our results, the initial seedling height at the beginning of the growing year positively influenced the annual height growth of Korean pine seedlings (Table 2). Although dealing with different coniferous tree species, positive correlations have also been observed at plantations of Japanese sugi (Cryptomeria japonica D. Don) and hinoki (Chamaecyparis obtusa (Sieb. et Zucc.) Endl.) when they were small in tree size [43]. Kiyono et al. [44] examined the early height growth of underplanted Japanese hinoki using a multiple regression analysis and achieved a better predictive accuracy of the model by including initial seedling height as an explanatory variable. In the United States, Moores et al. [45] found that initial seedling height had a significant effect on predicting the annual height growth of three shade-tolerant coniferous species, including balsam fir (Abies balsamea (L.) Mill), red spruce (Picea rubens Sarg.), and eastern hemlock (Tsuga canadensis (L.) Carr.). Similarly, in the case of Korean pine, the initial height of seedlings should be considered an important predictor for height growth modeling.

Overstory larch canopies significantly affected the seedling height growth of underplanted Korean pine 
(Table 2). As presented in Figure 4, seedlings planted in the open site (OPEN) showed superior height growth versus the underplanted seedlings. A relatively low light regime created by partial canopy closure may inhibit the height growth of underplanted Korean pine seedlings $[12,19]$. In eastern Liaoning, Liu and Wang [42] reported a seedling height of $82.2 \mathrm{~cm}$ at 4 years after planting in an open site, which is relatively small compared to our control site $(114.2 \mathrm{~cm}$ at OPEN). This is probably due to their investigations being conducted at a higher elevation site ( $684 \mathrm{~m}$ above sea level) where relatively small-sized seedlings were initially planted (13.3 $\mathrm{cm}$ on average).

Our results also indicated that the type of strip-cut has a significant effect on the height growth of underplanted Korean pine seedlings. We observed a general increasing trend of canopy openness as the strip-cut width got wider (Table 1). In the stand with the narrowest strip (i.e., $4.5 \mathrm{~m}$ ), the annual height growth was predicted to be approximately onehalf and the seedling height after 7 growing years was predicted to be one-third of those in the open site (Figures 4 and 5). Such a cramped strip-cut could not greatly improve the understory light conditions [16]. Although stand age affected canopy openness on equal strip-cut width (Table 1, probably through a change in stand density; [46]), its effect on seedling height growth was ambiguous. Despite its larger canopy openness, A17-W6.0 produced smaller height growth than A12-W6.0 (Figure 1). Available light for tree regeneration establishment (natural or artificial) can be increased through strip-cutting, but not so much as to promote competition by understory shrubs or herbaceous plants [9]. In addition to larch canopy conditions, the competitive effect of understory vegetation may be a factor for consideration in growth predictions.

We assume that the seedling height growth observed in the $4.5 \mathrm{~m}$ strip-cut is inadequate for forest management purposes. Because larger pine trees generally produce more cone crops [47], smaller height growth may cause economic loss by delaying cone production and the harvest of nuts. To secure preferred height growth, forest managers are recommended to consider wider strip-cuts for two-storied management of larch and Korean pine plantations. Although seedlings in the wider strip-cuts $(6.0-7.5 \mathrm{~m})$ had smaller predicted growths than in OPEN (Figure 4), the differences were not statistically significant (Table 2 ). By creating $6 \mathrm{~m}$ or wider strip-cuts, underplanted seedlings were predicted to reach breast height within 1-2 years of seedlings planted at open sites (Figure 5). Strip-cuts that are too wide, however, may negatively affect the growth and photosynthetic capacities of Korean pine as it increases in size [16]. The planting of Korean pine seedlings in wide openings may entail risks including understory competition [9], physiological drought [48], and early stem divergence [17]. Even though our model predicted greater height growth for Korean pine seedlings in wider strip-cuts, forestry practitioners should apply this research carefully.

This study was intended to quantitatively illustrate the height growth of underplanted Korean pine seedlings in strip-cut larch plantations in Northeast China. Our results, however, are limited to predicting height growth at the early growing stages; longitudinal studies within a site are needed for a more complete understanding of growth dynamics under partial larch canopies. Data of understory vegetation would be useful to examine the competitive effect on underplanted seedlings. Furthermore, site-specific conditions may have affected the results of this study. Further research should examine growth patterns under various other site conditions. Future studies should provide for a more fully developed understanding of Korean pine growth for the sustainable management of larch plantations in Northeast China.

\section{Conflict of Interests}

The authors declare that there is no conflict of interests regarding the publication of this paper.

\section{Acknowledgments}

The authors would like to thank Mr. Yanhui Sun at the Dabiangou Forest Farm of Qingyuan County for permitting them to conduct research at the study site. They also thank Ms. Juan Xue at the College of Forestry, Shenyang Agricultural University, for her assistance in field data collection. They are grateful to Mr. Shangjun Gao, Mr. Wanren Wang, Mr. Yan Wang, Mr. Xiaofei Chen, and Mr. Chuansheng Hou for sharing their knowledge of China's forestry practices. They wish to acknowledge anonymous reviewers for their helpful comments on an earlier version of this paper. This study was partly supported by the Alliance for Global Sustainability promotional office at the University of Tokyo, Japan.

\section{References}

[1] D. Yu, L. Zhou, W. Zhou et al., "Forest management in Northeast China: history, problems, and challenges," Environmental Management, vol. 48, no. 6, pp. 1122-1135, 2011.

[2] S. Liu, X. Li, and L. Niu, "The degradation of soil fertility in pure larch plantations in the northeastern part of China," Ecological Engineering, vol. 10, no. 1, pp. 75-86, 1998.

[3] C. Brasier and J. Webber, "Plant pathology: sudden larch death," Nature, vol. 466, no. 7308, pp. 824-825, 2010.

[4] Q. Mao, M. Watanabe, and T. Koike, "Growth characteristics of two promising tree species for afforestation, birch and larch in the northeastern part of Asia," Eurasian Journal of Forest Research, vol. 13, no. 2, pp. 69-76, 2010.

[5] H. Wang, Y. Uozumi, T. Ueki, J. Dong, and Q. Guan, "The present situation and problems about larch forest in China," Journal of Forest Planning, vol. 35, pp. 93-98, 2001 (Japanese).

[6] S. Shang, M. Yin, C. Wu et al., "Photosynthetic characteristics of four species of saplings planted in Larix olgensis forest," Journal of Northeast Forestry University, vol. 38, no. 7, pp. 36-38, 2010 (Chinese).

[7] S. Tatsuhara, "Modelling growth for two-storied stands: incorporating an effect of shading on the tree growth into growth and yield models," Journal of Forest Research, vol. 6, no. 4, pp. 231239, 2001.

[8] H. Spiecker, J. Hansen, E. Klimo, J. P. Skovsgaard, H. Sterba, and K. von Teuffel, Eds., Norway Spruce Conversion: Options and Consequences, Brill, Leiden, The Netherlands, 2004. 
[9] A. Paquette, A. Bouchard, and A. Cogliastro, "Survival and growth of under-planted trees: a meta-analysis across four biomes," Ecological Applications, vol. 16, no. 4, pp. 1575-1589, 2006.

[10] L. J. Zhou, The research on pure larch plantations induce to artificial multi-storied forest of Liaodong mountain area [M.S. thesis], Shenyang Agricultural University, 2012 (Chinese).

[11] Y.-R. Sun, J.-J. Zhu, L.-Z. Yu, Q.-L. Yan, and K. Wang, "Photosynthetic characteristics of Pinus koraiensis seedlings under different light regimes," Chinese Journal of Ecology, vol. 28, no. 5, pp. 850-857, 2009.

[12] J. Cong, H.-L. Shen, W.-H. Yang, S.-H. Fan, and Q. Zhang, "Effect of microenvironmental quantitative regulation on growth of Korean pine trees planted under secondary forest," Journal of Forestry Research, vol. 22, no. 2, pp. 175-181, 2011.

[13] C.-Z. Li and K.-G. Löfgren, "A theory of red pine (Pinus koraiensis) management for both timber and commercial seeds," Forest Science, vol. 46, no. 2, pp. 284-290, 2000.

[14] H. M. Rang, S. I. Choi, N. Sato, and H. Kim, "Study on Korean pine nut processors," Journal of the Faculty of Agriculture, Kyushu University, vol. 57, no. 2, pp. 489-498, 2012.

[15] J. H. Shin and D. K. Lee, "Growth phenology of various tree modules in a Pinus koraiensis S. et Z. plantation," in Proceedings of the Symposium on White Pine Provenances and Breeding, pp. 94-100, Montreal, Canada, August 1990.

[16] W. Wang, X. Yan, F. Shi, Y. Zu, and S. Nie, "A trial to accelerate afforestation of Korean pine forests using a strip-cutting method for deciduous broad-leaved secondary forests in northeastern China: an ecophysiological approach," Eurasian Journal of Forest Research, vol. 3, pp. 27-48, 2001.

[17] G. Jianping, L. Chuanrong, L. Ping, and L. Jingwen, "Study on the tree growth, architecture and stand structure of Korean pine plantation," Journal of Northeast Forestry University, vol. 6, no. 3, pp. 84-88, 1995.

[18] H.-L. Shen, J. Cong, P. Zhang et al., "Effect of opening degree regulation on diameter and height increment and aboveground bio-mass of Korean pine trees planted under secondary forest," Chinese Journal of Applied Ecology, vol. 22, no. 11, pp. 2781-2791, 2011.

[19] J. Miao, L.-Z. Yu, and Y.-R. Sun, "Effects of secondary forest canopy openness on the growth of Pinus koraiensis saplings in eastern Liaoning Province of Northeast China," Chinese Journal of Ecology, vol. 31, no. 9, pp. 2191-2196, 2012 (Chinese).

[20] Y. B. Zhou, Y. Yin, X. S. Liu, and Q. L. Wang, "Photosynthetic induction responses of Pinus koraiensis seedlings grown in different light environments," Journal of Forestry Research, vol. 15, no. 3, pp. 246-248, 2004.

[21] K. Makoto and T. Koike, "Effects of nitrogen supply on photosynthetic and anatomical changes in current-year needles of Pinus koraiensis seedlings grown under two irradiances," Photosynthetica, vol. 45, no. 1, pp. 99-104, 2007.

[22] D. H. Ji, S. Kitaoka, D. S. Choi, M. J. Yi, T. Hiura, and T. Koike, "Photosynthetic characteristic of Korean pine (Pinus koraiensis) seedlings naturally regenerated in Tomakomai Experimental Forest," Transactions of the Meeting in Hokkaido Branch of the Japanese Forest Society, vol. 56, pp. 37-39, 2008 (Japanese).

[23] Z. Wang and X.-H. Fan, "Effects of light intensity heterogeneity in gaps of broadleaved korean pine forest in changbai mountains on Pinus koraiensis seedlings growth," Chinese Journal of Applied Ecology, vol. 20, no. 5, pp. 1044-1050, 2009.

[24] W. Yin, M. Yin, L. Zhao, and L. Yang, "Research on the measurement of carbon storage in plantation tree trunks based on the carbon storage dynamic analysis method," International Journal of Forestry Research, vol. 2012, Article ID 626149, 10 pages, 2012.

[25] M.-F. Yin, L. Zhao, X.-F. Chen, S. Cao, and C.-S. Hou, "Carbon storage maturity age of Larix olgenisis and L. kaempferi," Chinese Journal of Applied Ecology, vol. 19, no. 12, pp. 2567-2571, 2008 (Chinese).

[26] S. Tatsumi, T. Owari, M. Yin, and L. Ning, "Neighborhood analysis of underplanted Korean pine demography in larch plantations: implications for uneven-aged management in northeast China," Forest Ecology and Management, vol. 322, pp. 10-18, 2014.

[27] G. W. Frazer, C. D. Canham, and K. P. Lertzman, Gap Light Analyzer (GLA): Imaging Software to Extract Canopy Structure and Gap Light Transmission Indices from True-Colour Fisheye Photographs, Users Manual and Program Documentation, Simon Fraser University, Burnaby, Canada; Institute of Ecosystem Studies, Millbrook, NY, USA, 1999.

[28] I. Gamache and S. Payette, "Height growth response of tree line black spruce to recent climate warming across the forest-tundra of eastern Canada," Journal of Ecology, vol. 92, no. 5, pp. 835$845,2004$.

[29] Y. Wang, K. Čufar, D. Eckstein, and E. Liang, "Variation of maximum tree height and annual shoot growth of smith fir at various elevations in the Sygera Mountains, southeastern Tibetan Plateau," PLoS ONE, vol. 7, no. 3, Article ID e31725, 2012.

[30] N. E. Breslow and D. G. Clayton, "Approximate inference in generalized linear mixed models," Journal of the American Statistical Association, vol. 88, no. 421, pp. 9-25, 1993.

[31] B. M. Bolker, M. E. Brooks, C. J. Clark et al., "Generalized linear mixed models: a practical guide for ecology and evolution," Trends in Ecology \& Evolution, vol. 24, no. 3, pp. 127-135, 2009.

[32] J. S. Clark, M. Wolosin, M. Dietze et al., "Tree growth inference and prediction from diameter censuses and ring widths," Ecological Applications, vol. 17, no. 7, pp. 1942-1953, 2007.

[33] H. Akaike, "Information theory and an extension of the maximum likelihood principle," in Proceedings of the 2nd International Symposium on Information Theory, B. N. Petrov and F. Caski, Eds., pp. 267-281, Akademiai Kiado, Budapest, Hungary, 1973.

[34] J. B. Johnson and K. S. Omland, "Model selection in ecology and evolution," Trends in Ecology \& Evolution, vol. 19, no. 2, pp. 101-108, 2004.

[35] S. Nakagawa and H. Schielzeth, "A general and simple method for obtaining $R^{2}$ from generalized linear mixed-effects models," Methods in Ecology and Evolution, vol. 4, no. 2, pp. 133-142, 2013.

[36] N. Timilsina and C. L. Staudhammer, "Individual tree-based diameter growth model of slash pine in Florida using nonlinear mixed modeling," Forest Science, vol. 59, no. 1, pp. 27-37, 2013.

[37] H. Temesgen, V. J. Monleon, and D. W. Hann, "Analysis and comparison of nonlinear tree height prediction strategies for Douglas-fir forests," Canadian Journal of Forest Research, vol. 38, no. 3, pp. 553-565, 2008.

[38] D. Bates, M. Maechler, B. Bolker, and S. Walker, lme4: Linear Mixed-Effects Models Using Eigen and S4, R Package Version 1.15, 2014, http://CRAN.R-project.org/package=lme4.

[39] A. Kuznetsova, P. B. Brockhoff, and R. H. B. Christensen, "ImerTest: Tests for Random and Fixed Effects for Linear Mixed Effect Models (lmer Objects of lme4 Package), R Package Version 2.0-6," 2014, http://CRAN.R-project.org/package=lmerTest.

[40] K. Bartoń, Multi-Model Inference: R Package 'MuMIn' Version 1.9.13, 2013, http://CRAN.R-project.org/package=MuMIn. 
[41] R Core Team, R: A Language and Environment for Statistical Computing, R Foundation for Statistical Computing, Vienna, Austria, 2014, http://www.R-project.org/.

[42] Q. Liu and J. Wang, "Height growth of Korean pine plantation sapling in Benxi, Liaoning Province, China," Journal of Forestry Research, vol. 22, no. 1, pp. 141-143, 2011.

[43] K. Tanaka, "A stochastic model of height growth in an even-aged pure forest stand: why is the coefficient of variation of the height distribution smaller than that of the diameter distribution?" Journal of the Japanese Forestry Society, vol. 70, no. 1, pp. 20-29, 1988.

[44] Y. Kiyono, H. Kushima, T. Igarashi, T. Ito, and S. Okuda, "An estimate of height growth of using initial height, relative light intensity and soil condition of understory Hinoki (Chamaecyparis obtusa)," in Proceedings of the Meeting in Kanto Branch of the Japanese Forestry Society, vol. 53, pp. 107-109, 2002 (Japanese).

[45] A. Moores, R. Seymour, and L. Kenefic, "Understory height growth dynamics in uneven-aged, mixed-species northern conifer stands," in Proceedings of the New England Society of American Foresters 84th Winter Meeting, pp. 12-14, Quebec, Canada, March 2004.

[46] S. E. Hale, C. Edwards, W. L. Mason, M. Price, and A. Peace, "Relationships between canopy transmittance and stand parameters in Sitka spruce and Scots pine stands in Britain," Forestry, vol. 82, no. 5, pp. 503-513, 2009.

[47] P. G. Krannitz and T. E. Duralia, "Cone and seed production in Pinus ponderosa: a review," Western North American Naturalist, vol. 64, no. 2, pp. 208-218, 2004.

[48] L. Chuanrong and L. Ping, "Study on improving the growth quality of planted seedling of Pinus koraiensis in initial stage," Journal of Northeast Forestry University, vol. 6, no. 3, pp. 79-83, 1995. 

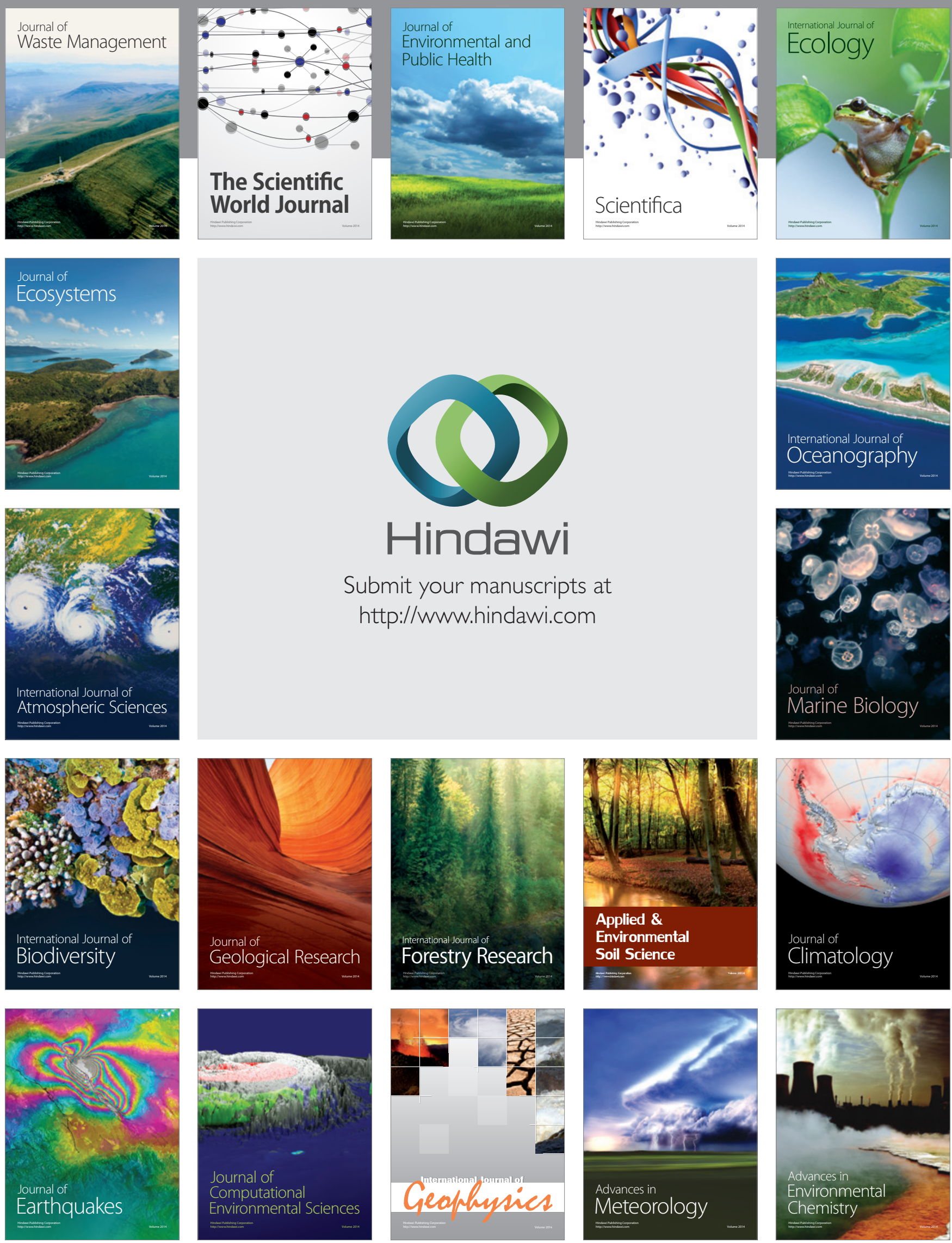